\title{
Pharmacokinetics of a Taste-Masked Prednisone Oral Microsphere Powder
}

\author{
Shoults CC ${ }^{1}$, Kearns GL ${ }^{2,3}$, Meyer AR ${ }^{1}$, Moran $\mathrm{J}^{2,4,5}$, D'Ann Pierce ${ }^{3}$, Abdel-Rahman SM ${ }^{6,7}$, Berkland CJ1,8 and Dormer NH ${ }^{1 \star}$ \\ ${ }^{1}$ Orbis Biosciences, Inc., Lenexa, KS, USA \\ ${ }^{2}$ Arkansas Children's Research Institute, Little Rock, AR, USA \\ ${ }^{3}$ Section of Pediatric Clinical Pharmacology and Toxicology, Department of Pediatrics, University of Arkansas for Medical Sciences, Little Rock, AR, USA \\ ${ }^{4}$ PinPoint Testing, LLC, Little Rock, AR, USA \\ ${ }^{5}$ Department of Pharmacology, University of Arkansas for Medical Sciences, Little Rock, AR, USA \\ ${ }^{6}$ Department of Pediatrics, University of Missouri - Kansas City, Kansas City, MO, USA \\ ${ }^{7}$ Division of Clinical Pharmacology, Toxicology and Therapeutic Innovation, Children's Mercy Hospital, Kansas City, MO, USA \\ ${ }^{8}$ Department of Pharmaceutical Chemistry, Department of Chemical and Petroleum Engineering, University of Kansas, Lawrence, KS, USA
}

\begin{abstract}
Many active pharmaceutical ingredients (APIs) face the challenge of palatability when administered orally. Tastemasking technologies often utilize coatings to help palatability but these coatings or agglomerations can negatively impact bioavailability. Orbis Biosciences, Inc. (Orbis) has developed a novel taste-masking technology that has previously been demonstrated to have virtually complete taste-masking of the extremely bitter API, prednisone. The next facet of development was to assess the pharmacokinetics (PK) and relative bioequivalence (BE) of prednisone from this new formulation. Presented here is a randomized, open-label, two products, two period and crossover study in fasted adults comparing $10 \mathrm{mg}$ prednisone taste-masked microspheres to a $10 \mathrm{mg}$ prednisone tablet. Fourteen (14) post-dose plasma concentrations obtained over a $12 \mathrm{~h}$ period were analyzed for prednisone and its metabolite, prednisolone, using a validated HPLC/MS/MS method. Bioavailability was assessed according to current United States' Food and Drug Administration (FDA) criteria. Results indicated that for both $\mathrm{C}_{\max }(90 \% \mathrm{Cl} ; 0.81-1.10)$ and $A \cup C_{\text {total }}(0.94-1.18)$, the microsphere formulation met bioavailability criteria for prednisone. For prednisolone, only $A \cup C_{\text {total }}$ met criteria for bioavailability. $C_{\text {max }}$ was lower $(90 \%$ confidence interval of $0.647-0.938$ for log transformed data) and time of $C_{\max }\left(T_{\max }\right)$ was delayed $(2.9 \pm 0.5 \mathrm{vs} .1 .8 \pm 1.0 \mathrm{~h}, \mathrm{p}=0.02)$ in the microsphere relative to the tablet formulation. In conclusion, the relative bioavailability of the novel microsphere formulation of prednisone was evident as compared to a commercially available tableted formulation of the drug.
\end{abstract}

Keywords: Bioavailability; Bioequivalence; Immediate release; Prednisone; Taste-masked; Microsphere; Sprinkle; Palatability

\section{Introduction}

An issue many oral active pharmaceutical ingredients (APIs) face is their inherent bitter flavour [1]. Taste-masking technologies are often called upon to help mask bitter flavour and increase the compliance associated with foul-tasting drugs. Traditional taste-masking technologies may utilize a secondary step to coat precursor particles made from hydrophilic excipients, ion-exchange resins, or solid dispersions, which can negatively impact the absorption of the drug in vivo and can impact the API's overall bioavailability [2,3]. A change in bioavailability of the active can lead to inability or difficulty matching the Food and Drug Administration's (FDA) bioequivalence parameters [4].

Oral dosage forms can coat the pill or place the API in a shell, however, this dosage form is not ideal for populations that require weight-based (e.g., $\mathrm{mg} / \mathrm{kg}$ or $\mathrm{mg} / \mathrm{m}^{2}$ ) dosing or for individual patients who have difficulty or aversion to swallowing pills. For instance, the FDA, the International Council on Harmonization (ICH) and the European Medical Authority (EMA) specify that paediatric drug formulations should be developed in paediatric-friendly formats (i.e. the dosage form must be ingestible by a child and be formulated to support compliance) [5-7]. Formulations that are not appropriate or designed for paediatric populations (e.g. tablets, capsules, foul-tasting liquids) can cause medication nonadherence that can negatively impact treatment efficacy [8]. The general lack of paediatric-specific drug products often leads to the preparation of extemporaneous formulations which frequently lack data regarding bioavailability, stability, palatability and safety [9]. Manipulations such as crushing, scoring, or adding excipients may affect stability, cause inaccurate dosing and be hazardous for the ersatz compounder. Thus, a pressing need exists to develop new formulation technology that would enable the creation of drug products with favourable organoleptic and physicochemical properties (e.g., stability, retention of potency) that permit accurate weight-based dosing in a novel dosage form.

An API commonly cited as extremely bitter and difficult to mask is prednisone [10,11]. This corticosteroid is used in paediatrics and adults for a plethora of indications including respiratory conditions, dermatologic diseases and allergic response. Crushing adult solid dosage forms to facilitate weight-based dosing of prednisone in paediatric patients or individuals with swallowing difficulties further exacerbates problems with palatability and acceptability (e.g., taste and mouth feel) Liquid formulations may overcome some of these issues, but often the API's inherent bitter taste is apparent, especially for children whose bitter taste receptors are more discriminating as compared to adults [12]. Recent research shows that children more genetically sensitive to bitter tastes are less likely to accept liquid drug formats as compared to

*Corresponding author: Nathan $\mathrm{H}$ Dormer, $\mathrm{PhD}$, Vice President, Research \& Development, Orbis Biosciences, Inc., Lenexa, KS 66214, USA, Tel: 913-544-1199; Ext: 204; E-mail: nate@orbisbio.com

Received August 15, 2017; Accepted October 10, 2017; Published October 20, 2017

Citation: Shoults CC, Kearns GL, Meyer AR, Moran J, D'Ann P, et al. (2017) Pharmacokinetics of a Taste-Masked Prednisone Oral Microsphere Powder. Bioequiv Availab 9: 547-554. doi: 10.4172/jbb.1000360

Copyright: () 2017 Shoults CC, et al. This is an open-access article distributed under the terms of the Creative Commons Attribution License, which permits unrestricted use, distribution, and reproduction in any medium, provided the original author and source are credited. 
their peers and that, overall, children report issues with taking liquid formulations due to taste [13].

Orbis Biosciences, Inc. (Orbis), produces taste-masked microspheres, utilizing an innovative manufacturing platform [1416]. which precisely controls size distributions to match the release of existing formulations. This precision particle fabrication technology was utilized to formulate a novel prednisone microsphere that has been previously demonstrated to produce effective and virtually complete taste-masking of the drug [17]. These microspheres could be utilized as a drug product intermediate with a liquid suspension final product or alone as a powder. The first human trial of relative bioavailability of this novel taste-masked prednisone powder formulation is reported here.

\section{Materials and Methods}

\section{Investigational product}

The test formulation was produced in accordance with U.S. FDA current Good Manufacturing Practices (cGMP) 21 Code of Federal Regulations Parts 210/211 under cGMP conditions at Orbis' facility in Lenexa, KS. The proprietary process involved mixing prednisone with a lipid excipient base co-melted with a reverse-enteric polymer, then processing said mixture through an acoustically-excited nozzle with coaxial nitrogen stream into a containment system. The resulting product was a free-flowing taste-masked prednisone-containing microsphere powder. The microsphere formulation for this study was developed to provide taste-masking without extended-release behaviour. Following manufacture, the microsphere product was tested to ensure conformity against the drug product's specifications and acceptance criteria before release and shipping to the clinical site.

USP dissolution: According to the FDA draft guidance recommended January of 2016, prednisone tablets can now utilize comparative dissolution testing on 12 dosage units of all strengths of the tablet in order to demonstrate bioequivalence [18]. This guidance is not applicable to the microsphere prednisone tested in this study due to dissolution method changes necessary to allow for the proper study of the microsphere. Specifically, the current FDA dissolution media is comprised solely of water, which is not ideal for the hydrophobic lipids utilized in the microsphere formulation. Testing dissolution with water media alone results in the microspheres floating on the surface of the dissolution bath. Additionally, the microsphere formulation incorporates a $\mathrm{pH}$-responsive excipient, requiring that the dissolution media be closer to gastric $\mathrm{pH}$ levels for drug release. Because of these two formulation characteristics, the final dissolution media had a low $\mathrm{pH}$ and contained surfactant.

Reagents and chemicals: All chemicals were at the least reagent grade and unless otherwise noted, were provided by Sigma-Aldrich (St. Louis, MO) and Fisher Scientific (Fairlawn, NJ).

Equipment: Dissolution was executed using a Vankel VK7000 Dissolution System (Santa Clara, CA), equipped with paddles. Samples were analysed using an Agilent 1100 liquid chromatography system, equipped with a variable wavelength detector (Santa Clara, CA). Instrument control and data acquisition and analysis was handled through Chromeleon (VER 7.2.2.6394).

Analytical standard preparation: United States Pharmacopoeia (USP) reference standard materials were used to prepare all analytical standards and quality control samples as per the USP Prednisone Tablet Monograph. All analytical standard solutions were stored at 5 degrees Centigrade $\left({ }^{\circ} \mathrm{C}\right)$ until needed.
Dissolution: The dissolution method from the USP Monograph for Prednisone Tablets was modified to more accurately display the release of the microsphere's drug product. $0.1 \%$ SLS (sodium dodecyl sulfate) and 0.1 one normal solution of hydrochloric acid $(\mathrm{N} \mathrm{HCl})$ were added to the dissolution media, with a paddle stir speed of 75 revolutions per min (rpm). Sample volumes of 3 milliliters $(\mathrm{mL})$ were withdrawn from each vessel at 10, 20, 30, 45, 60 and $120 \mathrm{~min}$ and filtered for high performance liquid chromatography (HPLC) analysis. This modified dissolution test method was validated.

Liquid chromatography: HPLC analysis was performed as outlined in the USP Monograph for Prednisone Tablets. Briefly, the method utilized 10 microliters $(\mu \mathrm{L})$ injections on a C-18 (L1) column (Thermo ODS Hypersil C18, $4.6 \times 150 \mathrm{~mm}, 5 \mu \mathrm{m}$ ) with ambient column and sample temperatures. The mobile phase comprised of HPLC grade tetrahydrofuran:methanol:water $(250: 62: 688 \mathrm{v} / \mathrm{v} / \mathrm{v})$ at a flow rate of 1.0 milliliters per $\mathrm{min}(\mathrm{mL} / \mathrm{min})$ (isocratic) and analytes were detected using a detector wavelength of 254 nanometer $(\mathrm{nm})$

\section{Human study design}

The FDA Guidance for Industry discussing bioavailability and bioequivalence for oral drug products was utilized to design the in vivo study described herein. This guidance allows for the execution of a pilot study to validate analytical methodology, assess variability and optimize sample collection time intervals [19]. Such a pilot study should consist of a single dose of the drug product as compared to a single dose of the reference listed drug. Additional detail on the study design is described in this section.

Informed consent and IRB: An independent Institutional Review Board (IRB) reviewed and approved the protocol and informed consent documents prior to the initiation of the study. All studyrelated procedures and data collection were performed after obtaining written informed consent from participants. The study was conducted in strict conformity with International Conference on Harmonisation (ICH) Good Clinical Practice guidelines and was fully compliant with Federal privacy regulations under the Health Insurance Portability and Accountability Act (HIPAA).

Study design: The study was an open label, randomized, singledose, two-treatment, two-sequence, two-period crossover design bioavailability/bioequivalence study under fasted conditions with a 6-day washout period between treatments. The test article was 10 milligrams (mg) of prednisone microspheres (Orbis Biosciences, Inc. Lenexa, KS) administered directly on to the tongue and the reference article was a $10 \mathrm{mg}$ prednisone tablet (Roxanne Laboratories, Columbus, $\mathrm{OH}$ ). Product order administration was dictated by simple randomization schedule so as to minimize any period effects in the assessment of relative bioavailability [SAS/STAT(R) version 9.2].

Participants: This study was conducted in the Paediatric Clinical Research Unit of the Arkansas Children's Hospital with healthy adult volunteers ages 18 to 24 years. All participants spoke English as their primary language and had a reading-level at or above grade 10. Exclusion criteria included one or more of the following: history of smoking or using any tobacco products; previous history of taste disturbance; any condition or dietary habit known to interfere with the sense of smell and taste; any apparent abnormality of the oral cavity (including tongue and teeth) and/or recent dental surgery within 7 days of administration of the study articles; any structural or functional abnormality of the upper gastrointestinal tract; ingestion of any medication or nutritional supplement (with exception of acetaminophen or hormonal oral 
contraceptives) in a $48 \mathrm{~h}$ period prior to study; history of any illness within the two weeks prior to study; history of autonomic dysfunction, bronchospastic disease or atopic allergy; known hypersensitivity (i.e., allergic reaction) to any drug, food coloring agent, or artificial sweetener; any history of participating in a clinical trial of a drug or device within a 30-day period from the time of study. All study participants were documented to have had a normal physical examination, screening electrocardiogram and vital signs (pulse, respiratory rate, blood pressure) before receiving any study article. For female subjects who had attained the age of menarche, a negative urine pregnancy test was also documented prior to drug administration.

Drug administration: Following an overnight fast of at least ten hours, study participants received either the test (microspheres) or reference (tablet) prednisone formulations. Volunteers maintained their fast for four hours after drug administration, although water was allowed ad lib during the study except for $1 \mathrm{~h}$ prior through $1 \mathrm{~h}$ post dose. The test formulation (10 $\mathrm{mg}$ of prednisone in microsphere format) was administered as a powder on pharmaceutical paper followed by two portions of water, each four ounces for a total of eight ounces of water. The two portions were given to facilitate oral clearance of the drug formulation. The reference formulation (a single $10 \mathrm{mg}$ prednisone tablet) was given with eight ounces of water. Both the test and reference formulation were administered to participants while they were seated upright; a position maintained for one hour after study article administration. Any participant who had an emesis event within two hours after administration of the test article was withdrawn from the study and replaced under the same randomization scheme.

Sampling and sample handling: Prior to administration of the study article, an indwelling silastic catheter (21 gauges, Becton Dickinson and Co., Franklin Lakes, NJ) was placed into a large vein either on the dorsum of the hand or the volar surface of the forearm. At that time, a pre-dose blood sample $(2 \mathrm{~mL})$ was obtained. Patency of the catheter was maintained with a sterile 0.9 percent sodium chloride $(\mathrm{NaCl})$ solution. After administration of the study articles, repeated venous blood samples ( $3 \mathrm{~mL}$ each) were obtained at the following postdose times: $0.25,0.5,1,1.5,2,2.5,3,4,5,6,7,8,10$ and $12 \mathrm{~h}$. During sampling, study participants were either seated or in the recumbent position and were not permitted to exercise. At four-hour intervals, vital signs and visual inspection of the venous cannula site were performed.

Before each sample was withdrawn using a plastic sterile syringe, the flush solution $(0.9 \% \mathrm{NaCl})$ and a small amount of blood (i.e., approximately $1.5 \mathrm{~mL}$ ) were removed and discarded to ensure that flush solution did not contaminate the analytical sample. Blood samples were immediately transferred to green top glass tubes containing sodium heparin (Becton Dickinson Co., Franklin Lakes, NJ) and mixed by gentle inversion ( 8 times). They were maintained at $4^{\circ} \mathrm{C}$ until centrifuged $\left(2,500 \mathrm{Xg}, 4^{\circ} \mathrm{C}\right.$ for $\left.5 \mathrm{~min}\right)$ to separate the plasma and cellular fractions; a period not exceeding $2 \mathrm{~h}$ from the time of collection. Plasma was then aspirated manually, placed into a labelled, screwcapped polypropylene vial (CryoVial', Fischer Scientific, St. Louis, MO) and immediately placed in a secure, $-20^{\circ} \mathrm{C}$ freezer for storage. At the end of each study period for each participant, the clinical research nurse coordinator validated sample integrity, labeling and reconciled it with the information contained on the case report forms.

\section{Bioanalytical method}

Reagents and chemicals: Analytical procedures were validated to rapidly quantify prednisone and prednisolone in human plasma with a high degree of accuracy and precision. The method used simple, automated sample preparation techniques that incorporated an isotopically-labeled internal standard (cortisol-d4). All chemicals were of at least reagent grade and unless otherwise noted, were provided by Sigma-Aldrich (St. Louis, MO), Fisher Scientific (Fairlawn, NJ), Biotage (Charlotte, NC). Blank, pooled human plasma void of prednisone and prednisolone contamination was screened prior to use.

Equipment: Supported liquid extraction procedures were optimized for 96-well plate processing on a PerkinElmer Zephyr G3 SPE Workstation (Waltham, MA). Sample extracts were analysed using an Agilent 1260 quaternary liquid chromatography system (Santa Clara, CA) coupled to an Agilent 6420 tandem mass spectrometer (Santa Clara, CA) (LC-MS/MS). Instrument control and data acquisition was handled through MassHunter LC/MS Data Acquisition (VER B.08.00). All data analysis was performed through MassHunter Quantitative Analysis (VER B.07.01 SP2).

Analytical standard preparation: Certified reference materials were used to prepare all prednisone and prednisolone analytical standards and quality control samples, which were prepared separately by weighing each analyte on a scale that was calibrated with National Institute of Standards and Technology traceable standards. Primary working calibration and quality control (QC) standards were prepared in a dimethyl sulfoxide (DMSO) stock solution $(5 \mu \mathrm{g} / \mathrm{mL})$. A certified reference material was also used to prepare a DMSO internal standard spiking solution containing the surrogate cortisol- $\mathrm{d} 4(2.5 \mu \mathrm{g} / \mathrm{mL})$. All analytical and internal standard solutions were stored at $-20^{\circ} \mathrm{C}$ until needed.

Matrixed matched plasma calibration standards were prepared by first serially diluting the primary working standard $(5 \mu \mathrm{g} / \mathrm{mL})$ with DMSO to make intermediate spiking solutions. Final working plasma standards ( 2.5 to $250 \mathrm{ng} / \mathrm{mL}$ ) were made by spiking $0.5 \mathrm{~mL}$ of plasma with $25 \mu \mathrm{L}$ of the appropriate intermediate spiking solution. QC material was prepared by a separate dilution scheme in plasma at three concentrations spanning the calibration range (QCL (low), QCM (medium), QCH (high)). All QC material was prepared independent of calibration standards. Prior to sample processing and analysis, $10 \mu \mathrm{L}$ of internal standard spiking solution was added to all analytical standards, QC material and unknown samples. $25 \mu \mathrm{L}$ of DMSO was added to unknown samples to normalize DMSO content in all specimens.

Liquid extraction of standards: All plasma calibration standards, QC material and unknown samples were processed identically by first diluting each sample 1:1 with ultrapure 18.2 Mega-ohm ${ }^{*} \mathrm{~cm}$ water and then loading the mixture, under gentle vacuum, on a Biotage ISOLUTE SLE $+400 \mu \mathrm{L}$ 96-well plate. Samples were allowed to equilibrate for 5 min before extracting two times with $900 \mu \mathrm{L}$ of ethyl acetate. Eluent was collected in deep 96-well plate reservoirs and evaporated to complete dryness at approximately $35^{\circ} \mathrm{C}$ under a constant flow of nitrogen. The remaining residue was reconstituted in $100 \mu \mathrm{L}$ of Mobile Phase A: Mobile Phase B (70:30) prior to analysis.

Liquid chromatography-tandem mass spectrometry: The LCMS/MS method utilized $10 \mu \mathrm{L}$ injections on a $3.5 \mu \mathrm{m}$ Agilent Eclipse Plus $\mathrm{C} 18$ analytical column $(2.1 \times 30 \mathrm{~mm})$ heated to $35^{\circ} \mathrm{C}$. Analytes were resolved at $0.4 \mathrm{~mL} / \mathrm{min}$ under isocratic conditions, 50:50 mixture of Mobile Phase A (5 mM ammonium acetate) and Mobile Phase B (100\% methanol). The analytical column was washed between each injection by ramping the mobile phase gradient to $95 \%$ mobile phase $\mathrm{B}$ and holding for $1 \mathrm{~min}$. The column was allowed to equilibrate at initial starting conditions for $2 \mathrm{~min}$ before the next sample was injected. Total run time was $5 \mathrm{~min}$, including column equilibration period between 
injections. The specific mass spectrometer parameters were as follows: positive mode; capillary voltage $3000 \mathrm{~V}$; nebulizer setting at 50 pounds per square inch (psi); gas temperature of $350^{\circ} \mathrm{C}$; gas flow rate of $13 \mathrm{~L} / \mathrm{min}$ and autosampler temperature of $4^{\circ} \mathrm{C}$. Two transitions were monitored for each analyte in unknown samples. Ion ratios were matched to those of calibration standards to ensure interfering metabolites and other compounds were resolved. To ensure carryover was not present, matrix-matched samples containing no calibration standard material were injected and blanks were injected following analysis of a known high-concentration sample (i.e., high QC, QCH). Analyte parameters are illustrated in Table 1.

Analytical method validation: Accuracy and precision were determined using QC samples prepared during six single, independent experiments performed over several non-consecutive days. Accuracy was calculated as the absolute percent relative error for each of the expected QC concentrations. Analytical precision was calculated as the coefficient of variation $(\% \mathrm{CV})$ for replicate measurements at the three QC concentrations. The lower limit of detection was defined at less than the lowest calibrator $(2.5 \mathrm{ng} / \mathrm{mL})$ and the lower limit of quantitation (LLOQ) was calculated as 3 times the standard deviation of the lowest quality control. Table 2 provides a summary of linear ranges, correlation coefficients, detection limits and quantification limits for prednisone and prednisolone.

\section{Pharmacokinetic and statistical analyses}

Pharmacokinetic analyses were conducted using Kinetica version 5.1 (Thermo Electron, Philadelphia, PA). Prednisone and prednisolone plasma concentration versus time data were curve fit using a peeling algorithm to generate initial monoexponential parameter estimates. Final estimates of the terminal elimination rate constant $(\lambda z)$ were determined from an iterative, linear least squares regression algorithm. A model-independent approach was used and parameters of interest determined as described below.

Individual maximum plasma concentration $\left(\mathrm{C}_{\max }\right)$ and time to reach the maxium plasma concentration $\left(\mathrm{T}_{\max }\right)$ were obtained by direct examination of the plasma concentration versus time profile. The area under the plasma concentration versus time curve during the sampling period $\left(\mathrm{AUC}_{0-\mathrm{n}}\right)$ was calculated using the mixed log-linear method

\begin{tabular}{|c|c|c|c|c|c|}
\hline Analyte & $\begin{array}{c}\text { Q1 } \\
(\mathbf{m} / \mathbf{z})\end{array}$ & $\mathbf{Q 3 ~}_{\mathbf{~ ( m / z )}}$ & $\begin{array}{c}\text { Fragmentor } \\
\mathbf{( V )}\end{array}$ & $\begin{array}{c}\text { Collision } \\
\text { energy } \mathbf{( V )}\end{array}$ & $\begin{array}{c}\text { Cell } \\
\text { accelerator (V) }\end{array}$ \\
\hline Prednisone & 359.2 & $341.3^{\star}$ & 99 & 9 & 2 \\
\cline { 3 - 6 } & & $200.4^{\wedge}$ & 99 & 150 & 2 \\
\hline Prednisolone & \multirow{2}{*}{361.2} & $343.3^{\star}$ & 89 & 13 & 2 \\
\cline { 3 - 6 } & & $147.0^{\wedge}$ & 89 & 37 & 2 \\
\hline Cortisol-d $_{4}$ & 367.2 & 121 & 109 & 21 & 2 \\
\hline
\end{tabular}

'Denotes quantifier ion; ^ Denotes confirmation ion

Table 1: Analyte parameters for the bioanalytical method.

\begin{tabular}{|l|l|l|l|l|l|}
\hline Analyte & $\begin{array}{l}\text { Surrogate } \\
\text { IS }\end{array}$ & $\begin{array}{l}\text { Linear working } \\
\text { range }(\mathbf{n g} / \mathbf{m L})\end{array}$ & $\begin{array}{l}\text { Average } \mathbf{r}^{2} \\
\text { value }\end{array}$ & $\begin{array}{l}\text { L.O.D. }^{\text {a }} \\
\mathbf{( n g} / \mathbf{m L})\end{array}$ & $\begin{array}{l}\text { L.O.Q. }^{\text {b }} \\
\mathbf{( n g} / \mathbf{m L})\end{array}$ \\
\hline Prednisone & Cortisol-d4 & $2.5-250$ & 0.9967 & $<2.5$ & 5.0 \\
\hline Prednisolone & Cortisol-d4 & $2.5-250$ & 0.9926 & $<2.5$ & 5.0 \\
\hline
\end{tabular}

'Data are based on 5 single, independent experiments conducted on multiple, nonconsecutive days

${ }^{a}$ LOD, Lower limit of detection; ${ }^{b}$ LLQ, Lower limit of quantification, calculated as 3 times the standard deviation of the quality control low for each analyte. Estimated values for prednisone and prednisolone are 2.7 and 3.9, respectively. However, LOQs were administratively defined as $5.0 \mathrm{ng} / \mathrm{ml}$ because laboratory standard practice is to establish LOQs within $3 X$ of the lowest QC evaluated $(10 \mathrm{ng} / \mathrm{ml})$.

Table 2: Summary of linear ranges, correlation coefficients, detection limits, and quantification limits for prednisone and prednisolone* where $\mathrm{n}$ refers to the final sampling time with quantifiable prednisone or prednisolone concentrations. Extrapolation of the AUC to infinity $\left(\mathrm{AUC}_{0-\infty}\right)$ was achieved by the summation of $\mathrm{AUC}_{0-\mathrm{n}}+\mathrm{Cp}_{\mathrm{n} / \mathrm{z} z}$, where $\mathrm{Cp}$ is the last observable plasma concentration calculated from the curve fit and $\lambda z$ is the apparent terminal elimination rate constant. Additional model-independent parameters that were determined included; area under the moment curve (AUMC), half-life $\left(\mathrm{t}_{1 / 2}\right)$ and mean residence time (MRT).

Prednisone and prednisolone pharmacokinetic data for the study cohort were examined using standard descriptive statistics (i.e., arithmetic mean, geometric mean, standard deviation, coefficient of variation). A repeated measures analysis of variance model was employed to determine treatment, period and sequence effects for the resultant primary and secondary pharmacokinetic parameter estimates. Pharmacokinetic parameters reflective of absorption $\left(\mathrm{C}_{\max }, \mathrm{AUC}_{0-\mathrm{n}}\right.$, $\mathrm{AUC}_{0-\infty}$ ) were log-transformed using the natural logarithm, the $90 \%$ confidence intervals for the difference in the means calculated and the antilog of the confidence limits evaluated against the pre-established bioequivalence criteria set forth by the Food and Drug Administration [20]. A test formulation with a confidence interval between 0.80 and 1.25 would be considered bioequivalent with the reference formulation. The significance limit for all statistical analyses was set at $\alpha=0.05$. All analyses were performed in SPSS version 23 (IBM SPSS, Chicago, IL).

\section{Results}

\section{Investigational product}

The microspheres in this study had a volume-weighed average diameter, $\mathrm{d}(4,3)$, of $216 \mu \mathrm{m}$ with a d90, d50 and d10 of $264 \mu \mathrm{m}, 213$ $\mu \mathrm{m}$ and $171 \mu \mathrm{m}$, respectively. Specifically, $90 \%$ of the particles were below 264 micrometers, 50\% were below 213 micrometers and 10\% were below 171 micrometers. Prednisone content in the microsphere product was tailored to be approximately $5 \% \mathrm{w} / \mathrm{w}$. Dissolution of tastemasked microspheres in vitro showed greater than $80 \%$ release of prednisone within $30 \mathrm{~min}$, whereas $80 \%$ release of prednisone from the RLD tablet occurred in $10 \mathrm{~min}$, using the modified dissolution method. During method development, the USP dissolution method was also tested. Here, dissolution of taste-masked microspheres showed less than $2.1 \%$ release of prednisone within $30 \mathrm{~min}$, whereas $80 \%$ release of prednisone from the RLD tablet occurred in 10 min (Figure 1).

\section{Dosing of human subjects}

Ten subjects initially completed dose administration and one of those subjects (Subject 009) was withdrawn due to emesis within one hour of dosing. Subject 009 was dosed with the reference drug (Roxane tablet) and was withdrawn from the study on Day 1 due to vomiting. The emesis event was deemed unrelated to the reference product as the subject had taken her daily dose of oral hormonal contraceptive and had a prior history of emesis associated with taking the contraceptive on an empty stomach. Subject 009 was replaced using the same randomization sequence. In total, eleven subjects were recruited during the study period, with ten completing the study in full. The subject population was constituted by adults and equally balanced with respect to gender. Nine of the eleven participants were Caucasian with the remaining two African-American.

No serious adverse events occurred during the study. All adverse events are listed in Tables 3 and 4 . Whether an adverse event was related to the reference or investigational product was determined by the primary-or sub-investigator on a case-by-case basis. All volunteers were screened and approved as healthy prior to dosing and no clinically 
Citation: Shoults CC, Kearns GL, Meyer AR, Moran J, D'Ann P, et al. (2017) Pharmacokinetics of a Taste-Masked Prednisone Oral Microsphere Powder. J Bioequiv Availab 9: 547-554. doi: 10.4172/jbb.1000360

significant vital signs data were observed during this study.

\section{Pharmacokinetics of prednisone}

Bioanalytical method validation results are provided in Table 3, including summary of quality control recoveries and precision data for prednisone and prednisolone. Maximum observed prednisone concentrations $\left(\mathrm{C}_{\max }\right)$ in the current study ranged from 19.8 to $47.4 \mathrm{ng} /$ $\mathrm{mL}$ for the microsphere product and from 22.6 to $40.8 \mathrm{ng} / \mathrm{mL}$ for the reference listed drug (RLD) tablet. These values occurred (apparent $\mathrm{T}_{\max }$ ) anywhere from $2.5 \mathrm{~h}$ to $4.0 \mathrm{~h}$ post-ingestion for the microsphere product and from $0.5 \mathrm{~h}$ to $4.0 \mathrm{~h}$ for the RLD tablet. Values for total area under the curve $\left(\mathrm{AUC}_{0-\infty}\right)$ for the microsphere product ranged from 131.8 to $317.0 \mathrm{ng}^{\star} \mathrm{hr} / \mathrm{mL}$ and from 134.8 to $251.8 \mathrm{ng}{ }^{\star} \mathrm{hr} / \mathrm{mL}$ for the RLD tablet.

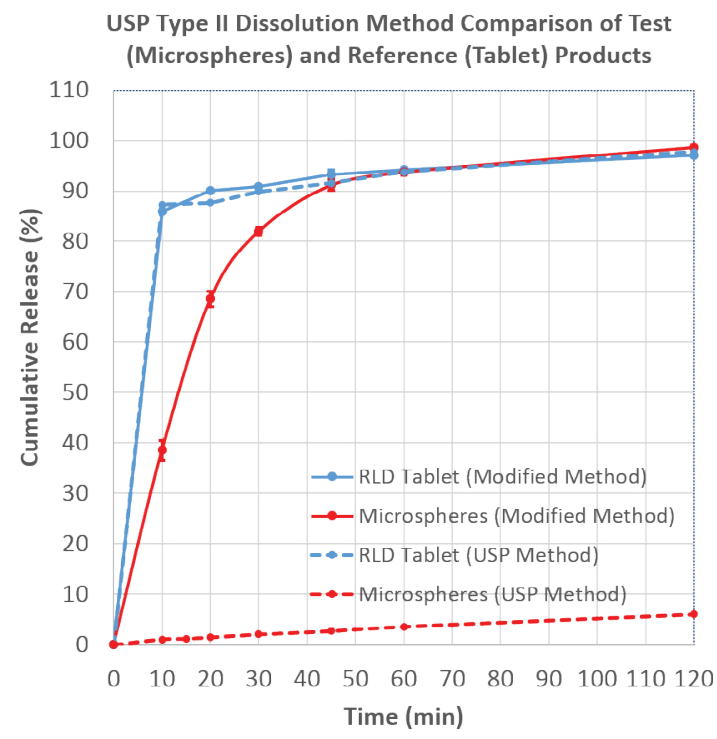

Figure 1: (In color) USP Type II dissolution of microspheres (red) versus tablet (blue) using the modified dissolution method (solid) and the USP dissolution method (dashed).
Extrapolation for the $\mathrm{AUC}_{0-\infty}$ values did not exceed $30.0 \%$ and $15.2 \%$ for the microsphere and RLD tablet groups, respectively. No period or sequence effects were observed for the primary pharmacokinetic parameter estimates (e.g. $\mathrm{C}_{\max }, \mathrm{AUC}_{0-\mathrm{n}}, \mathrm{AUC}_{0-\infty}$ ) of prednisone. No differences in primary pharmacokinetic parameters between treatments were observed for prednisone. Composite parameter estimates can be seen in Table 5, whereas prednisone plasma concentration as a function of time for the two treatments are displayed in Figure 2.

\section{Pharmacokinetics of prednisolone}

Maximum prednisolone concentrations $\left(\mathrm{C}_{\max }\right)$ in the current study ranged from 103.5 to $357.0 \mathrm{ng} / \mathrm{mL}$ for the microsphere product and from 120.8 to $430.0 \mathrm{ng} / \mathrm{mL}$ for the RLD tablet. These values occurred $\left(\mathrm{T}_{\max }\right)$ anywhere from $2.0 \mathrm{~h}$ to $4.0 \mathrm{~h}$ for the microsphere product and from $0.5 \mathrm{~h}$ to $4.0 \mathrm{~h}$ for the RLD tablet. Values for total area under the curve $\left(\mathrm{AUC}_{0-\infty}\right)$ for the microsphere product ranged from 610.6 to $2280.4 \mathrm{ng}^{*} \mathrm{hr} / \mathrm{mL}$ and from 590.2 to $2458.3 \mathrm{ng}{ }^{*} \mathrm{hr} / \mathrm{mL}$ for the RLD tablet. Extrapolation for the $\mathrm{AUC}_{0-\infty}$ values did not exceed $14.4 \%$ and $13.0 \%$ for the microsphere and RLD tablet groups, respectively. No period or sequence effects were observed for the primary pharmacokinetic parameter estimates (e.g. $\mathrm{C}_{\max }, \mathrm{AUC}_{0-\mathrm{n}}, \mathrm{AUC}_{0-\infty}$ ) of prednisolone, although they were noted for the secondary parameter mean residence time. A significant $(p<0.05)$ difference between treatments was observed for $\log$ transformed $\mathrm{C}_{\max }$ of prednisolone with lower concentrations observed after administration of the test formulation with a $90 \%$ confidence interval of 0.647-0.938. Composite parameter estimates can be seen in Table 6 and prednisolone plasma concentration as a function of time for the two treatments are displayed in Figure 3.

\section{Discussion}

There are many approaches to taste-masking foul-tasting drugs. The review of commonly used taste-masking techniques by Cram, et al. notes that modifying the drug through prodrugs, salts and polymorphs; modification of formulation $\mathrm{pH}$; barrier approaches utilizing polymer encapsulation, viscous or lipophilic vehicles; and drug complexes utilizing ion exchange resins or cyclodextrins all have the risk of impacting bio-performance [21]. The microspheres tested in this study

\begin{tabular}{|c|c|c|c|c|c|c|c|c|c|c|c|c|}
\hline & \multicolumn{4}{|c|}{ QC High $250 \mathrm{ng}$} & \multicolumn{4}{|c|}{ QC Mid $100 \mathrm{ng}$} & \multicolumn{4}{|c|}{ QC Low $10 \mathrm{ng}$} \\
\hline & $\begin{array}{c}\text { Conc. } \pm \text { SD (ng/ } \\
\mathrm{mL})\end{array}$ & $\begin{array}{l}\text { Between-Run } \\
\% C V\end{array}$ & $\begin{array}{l}\text { Within-Run } \\
\% C V\end{array}$ & $\%$ RE & $\begin{array}{c}\text { Conc. } \pm \text { SD (ng/ } \\
\mathrm{mL})\end{array}$ & $\begin{array}{c}\text { Between-Run } \\
\% \mathrm{CV}\end{array}$ & $\begin{array}{l}\text { Within-Run } \\
\% C V\end{array}$ & $\% \mathrm{RE}$ & $\begin{array}{c}\text { Conc..tSD } \\
(\mathrm{ng} / \mathrm{mL})\end{array}$ & $\begin{array}{l}\text { Between- } \\
\text { Run \%CV }\end{array}$ & $\begin{array}{l}\text { Within-Run } \\
\% \mathrm{CV}\end{array}$ & $\% R E$ \\
\hline 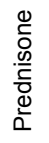 & $233.8 \pm 17.5$ & 7.5 & 8.2 & 6.5 & $92.9 \pm 5.6$ & 6.0 & 6.3 & 7.1 & $10.4 \pm 0.9$ & 8.3 & 7.6 & 4.3 \\
\hline 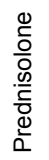 & $227.7 \pm 16.2$ & 7.1 & 7.6 & 8.9 & $89.5 \pm 5.5$ & 6.1 & 6.5 & 10.5 & $10.4 \pm 1.3$ & 12.3 & 9.5 & 4.1 \\
\hline
\end{tabular}

'Data are based on 5 single, independent experiments conducted on multiple, nonconsecutive days

Table 3: Summary of quality control recoveries and precision data for prednisone and prednisolone*

\begin{tabular}{|c|c|c|c|}
\hline Subject number & Dosed with reference or investigational product & Adverse event description & AE related to study product? \\
\hline 008 & Investigational Product (microsphere) & Headache \\
\hline 009 & Reference (tablet) & Nausea with Emesis \\
\hline 010 & Reference (tablet) & Headache & Itching (pruritus) \\
\hline 010 & Reference (tablet) & Unlikely & Not related \\
\hline 011 & Reference (tablet) & Unlikely & \\
\hline
\end{tabular}

Table 4: Comprehensive list of adverse events and relation to dosed study product. 
Citation: Shoults CC, Kearns GL, Meyer AR, Moran J, D’Ann P, et al. (2017) Pharmacokinetics of a Taste-Masked Prednisone Oral Microsphere Powder. J Bioequiv Availab 9: 547-554. doi: 10.4172/jbb.1000360
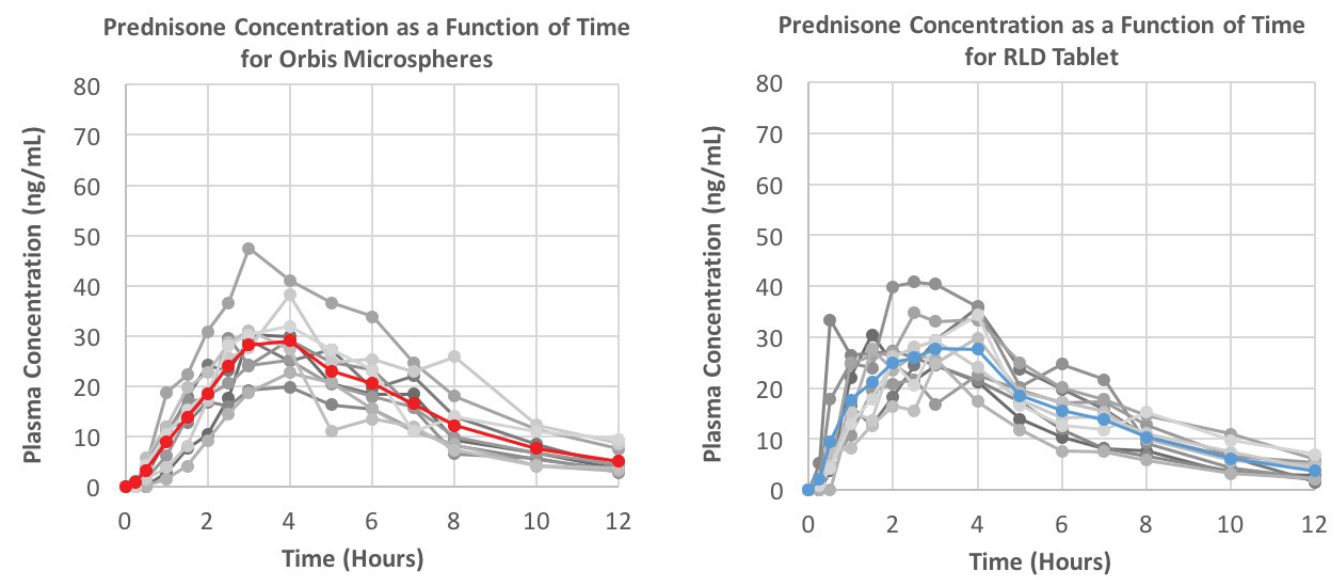

Figure 2: (In color) Plasma vs. time profiles of prednisone in the population (grey) and average for microspheres (red) and the RLD tablet (blue)

\begin{tabular}{|c|c|c|c|}
\hline Parameter & Overall & Test & RLD \\
\hline \multirow{2}{*}{$\mathbf{C}_{\max (n g / m L)}$} & $31.2 \pm 6.5$ & $30.5 \pm 7.8$ & $31.9 \pm 5.1$ \\
\hline & $(20.70)$ & $(25.70)$ & (15.90) \\
\hline \multirow[t]{2}{*}{$\mathbf{T}_{\max (\mathrm{hr})}$} & $3.1 \pm 1.0$ & $3.5 \pm 0.6$ & $2.7 \pm 1.3$ \\
\hline & (33.30) & (17.30) & (46.30) \\
\hline \multirow[t]{2}{*}{ AUC $_{0-n\left(n g^{*} h r / m L\right)}$} & $177.94 \pm 40.04$ & $181.06 \pm 48.42$ & $174.82 \pm 31.91$ \\
\hline & $(22.50)$ & $(26.70)$ & $(18.30)$ \\
\hline \multirow{2}{*}{ AUC $_{0 \cdots \infty}(\mathrm{ng} \mathrm{hr} / \mathrm{mL})$} & $197.73 \pm 50.11$ & $205.34 \pm 62.34$ & $190.11 \pm 35.86$ \\
\hline & (25.30) & $(30.40)$ & $(18.90)$ \\
\hline \multirow[t]{2}{*}{$\% A U C_{\text {ext }}$} & $9.3 \pm 5.9$ & $10.7 \pm 7.1$ & $7.8 \pm 4.3$ \\
\hline & $(63.40)$ & $(65.90)$ & $(54.60)$ \\
\hline \multirow[t]{2}{*}{ AUMC $_{0-n\left(n g^{*} h r / m L\right)}^{2}$} & $883.07 \pm 240.21$ & $943.63 \pm 279.77$ & $822.50 \pm 188.1$ \\
\hline & $(27.20)$ & $(29.60)$ & $(22.90)$ \\
\hline \multirow[t]{2}{*}{ AUMC $C_{0-\infty}\left(\mathrm{ng}^{*} \mathrm{hr}^{2} / \mathrm{mL}\right)$} & $1221.80 \pm 536.51$ & $1375.75 \pm 674.09$ & $\begin{array}{c}1067.84 \pm \\
317.18\end{array}$ \\
\hline & $(43.90)$ & $(49.00)$ & $(29.70)$ \\
\hline \multirow[t]{2}{*}{$\lambda \mathbf{z}_{(1 / \mathrm{hr})}$} & $0.262 \pm 0.066$ & $0.247 \pm 0.062$ & $0.277 \pm 0.070$ \\
\hline & $(25.30)$ & $(25.20)$ & $(25.20)$ \\
\hline \multirow[t]{2}{*}{$\mathbf{T}_{1 / 2(\mathrm{hr})}$} & $2.8 \pm 1.0$ & $3.1 \pm 1.3$ & $2.6 \pm 0.5$ \\
\hline & $(34.40)$ & $(41.30)$ & $(20.90)$ \\
\hline \multirow[t]{2}{*}{ MRT $_{(\mathrm{hr})}$} & $6.0 \pm 1.2$ & $6.5 \pm 1.4$ & $5.6 \pm 0.9$ \\
\hline & (20.40) & $(21.00)$ & $(16.60)$ \\
\hline
\end{tabular}

\section{Acronym list}

$\mathrm{C}_{\max }:$ Maximum plasma prednisone concentration;

$\mathrm{T}_{\max }^{\max }$ : Time to reach maximum prednisone plasma concentration following drug administration;

AUC : Area under the prednisone plasma concentration-time curve from time zero to the last measurable concentration;

AUC : Area under the prednisone plasma concentration-time curve;

$\% \mathrm{AUC}_{\text {ext: }}$ Area under the prednisone plasma concentration-time curve extrapolated from time $t$ to infinity as a percentage of total AUC;

AUMC $_{0-n}$ : Area under the first moment of the prednisone plasma concentration-

time curve from zero to the last measurable concentration;

AUMC $_{0 .}$ : Area under the first moment of the prednisone plasma concentrationtime curve from zero to infinity;

$\lambda_{z}$ : Terminal disposition rate constant;

$\mathrm{T}_{1 / 2}$ : Elimination half-life;

MRT: Mean residence time

Table 5: Composite prednisone pharmacokinetic parameter estimates represented as the Mean \pm standard deviation and (\% coefficient of variation) overall and by treatment.

relied on taste-masking technology utilizing the barrier approach through coating the drug in $\mathrm{pH}$ responsive polymers and thereby creating a barrier between the bitter API and the surface of the tongue.

\begin{tabular}{|c|c|c|c|}
\hline Parameter & Overall & Test & Reference \\
\hline \multirow{2}{*}{$C_{\max (n g / m L)}$} & $235.1 \pm 101.9$ & $206.9 \pm 94.4$ & $263.4 \pm 106.0$ \\
\hline & (43.30) & $(45.60)$ & (40.30) \\
\hline \multirow[t]{2}{*}{$\mathbf{T}_{\max (\mathrm{hr})}$} & $2.3 \pm 1.0$ & $2.9 \pm 0.5$ & $1.8 \pm 1.0$ \\
\hline & $(41.70)$ & $(18.60)$ & $(57.70)$ \\
\hline \multirow[t]{2}{*}{ AUC $_{0-n\left(n g^{*} h r / m L\right)}$} & $1167.43 \pm 607.55$ & $1150.15 \pm 597.02$ & $1184.70 \pm 649.73$ \\
\hline & $(52.00)$ & $(51.90)$ & $(54.80)$ \\
\hline \multirow[t]{2}{*}{ AUC $_{0-\infty}\left(n g^{*} h r / m L\right)$} & $1278.37 \pm 687.90$ & $1272.56 \pm 676.89$ & $1284.18 \pm 735.34$ \\
\hline & $(53.80)$ & $(53.20)$ & $(57.30)$ \\
\hline \multirow[t]{2}{*}{$\% A U C$ ext } & $7.9 \pm 3.5$ & $8.9 \pm 3.1$ & $6.9 \pm 3.7$ \\
\hline & $(44.20)$ & $(35.20)$ & $(53.50)$ \\
\hline \multirow[t]{2}{*}{ AUMC $_{0-\mathrm{n}\left(n g^{*} h r / m L\right)}{ }^{2}$} & $5138.52 \pm 2882.68$ & $5319.44 \pm 2823.71$ & $4957.61 \pm 3081.72$ \\
\hline & $(56.10)$ & $(53.10)$ & $(62.20)$ \\
\hline \multirow[t]{2}{*}{ AUMC $\left._{0-\infty\left(n g^{*} h r\right.}^{2} / \mathrm{mL}\right)$} & $6971.05 \pm 4307.86$ & $7358.96 \pm 4276.19$ & $6583.13 \pm 4534.00$ \\
\hline & $(61.80)$ & $(58.10)$ & $(68.90)$ \\
\hline \multirow[t]{2}{*}{$\lambda \mathbf{z}_{(1 / \mathrm{hr})}$} & $0.244 \pm 0.055$ & $0.228 \pm 0.036$ & $0.260 \pm 0.067$ \\
\hline & $(22.50)$ & $(15.60)$ & $(25.90)$ \\
\hline \multirow[t]{2}{*}{$\mathbf{T}_{1 / 2(\mathrm{hr})}$} & $3.0 \pm 0.7$ & $3.1 \pm 0.5$ & $2.8 \pm 0.8$ \\
\hline & $(22.10)$ & $(14.70)$ & $(28.60)$ \\
\hline \multirow[t]{2}{*}{ MRT $_{(\mathrm{hr})}$} & $5.3 \pm 0.8$ & $5.6 \pm 0.7$ & $4.9 \pm 0.8$ \\
\hline & $(15.00)$ & $(11.60)$ & $(15.70)$ \\
\hline \multicolumn{4}{|c|}{ 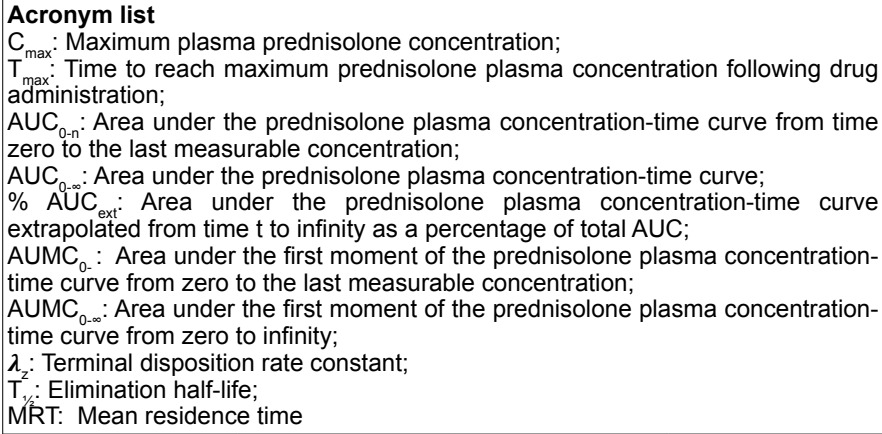 } \\
\hline
\end{tabular}

Table 6: Composite prednisolone pharmacokinetic parameter estimates represented as the Mean \pm standard deviation and (\% coefficient of variation) overall and by treatment.

The data provided herein summarize the results of a single-dose study comparing a commercially available prednisone tablet $(10 \mathrm{mg}$, Roxane Laboratories) to the proprietary, taste-masked, prednisone microsphere powder administered at $10 \mathrm{mg}$ strength. A model-independent approach 

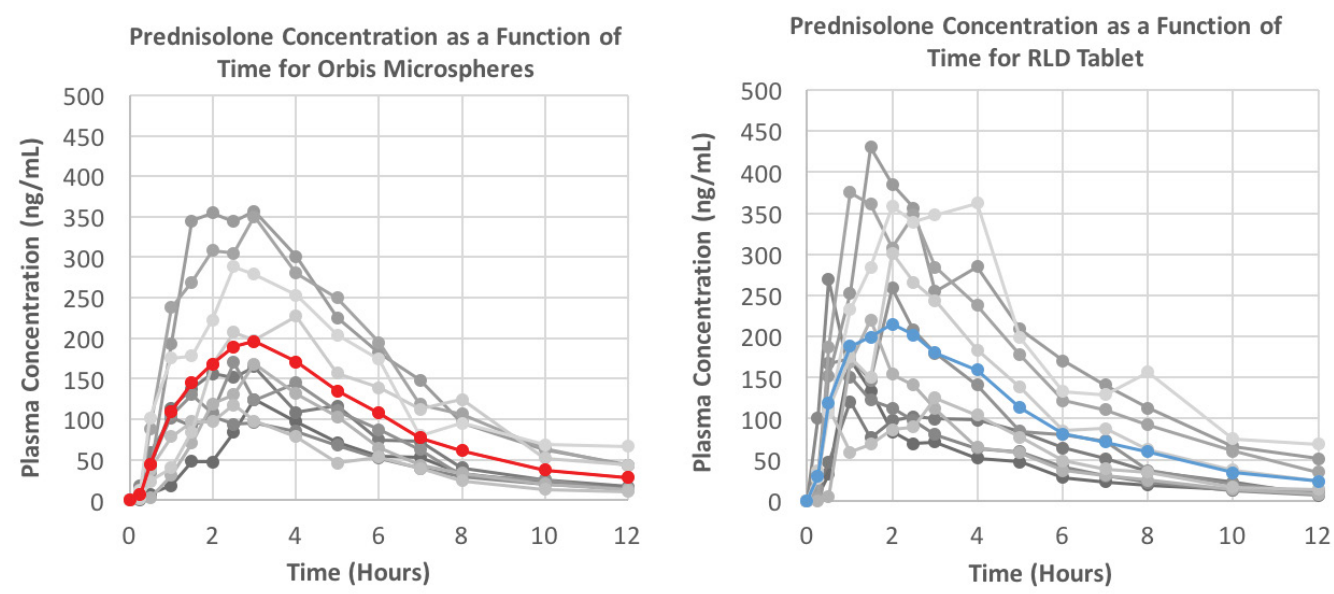

Figure 3: (In color) Plasma vs. time profiles of prednisolone in the population (grey) and average for microspheres (red) and the RLD tablet (blue).

was used to describe prednisone and prednisolone bio-disposition in all subjects and to generate parameter estimates used to assess relative bioavailability. Safety and efficacy profiles of the taste-masked powder were expected to reflect the pharmacodynamic attributes established with the reference tablet at comparable levels of systemic exposure. Though $\mathrm{C}_{\max }$ and $\mathrm{T}_{\max }$ of the active moiety (i.e. prednisolone) were lower and delayed after administration of the taste-masked oral prednisone powder, relative to the RLD tablet, the two formulations exhibited comparable total body exposure profiles after administration of a single oral dose in the fasted state.

The present study analyzed both prednisone and prednisolone to determine bioavailability and bioequivalence. Prednisone is converted to prednisolone by the enzyme $11 \beta$-hydroxydehydrogenase which converts prednisone's 11-oxo group to $11 \beta$-hydroxyl and creates prednisolone, the biologically active moiety [22]. Though this conversion would not be affected by polymers encapsulating prednisone in the taste-masked microencapsulated drug, the release of prednisone may be impaired and create a delay in the conversion of prednisone to prednisolone. The bioavailability of prednisolone is of primary importance when interpreting the results of this bioavailability (bioequivalence) study given its bioactivity profile.

Attributing the slight delay and magnitude of peak metabolite concentrations to a single cause is difficult with such a modest sample size, but may be a result of the taste-masked nature of the prednisone microsphere powder. Specifically, formulation modifications to include lower molecular weight components or substitution of water-soluble excipients could potentially lend to faster release kinetics in vitro and in vivo, which would more closely mimic the RLD tablet. Any such modifications to the test formulation, however, could compromise the taste-masking nature of the powder. Moreover, subsequent clinical studies with larger populations will more accurately illustrate if the metabolite pharmacokinetic anomalies seen herein are withstanding and not simply an artefact of sample size.

\section{Conclusion}

The current study described the comparison of a taste-masked prednisone microsphere powder to a commercially available RLD tablet of equivalent strength. Results revealed bioequivalent total body exposure profiles between the two formularies despite a slightly lower and delayed metabolite $\mathrm{C}_{\text {max }}$, which may be linked to small sample size (i.e. ten subjects). The importance of creating paediatric-and geriatricfriendly dosage forms that are palatable, dose-titratable and efficacious is a current focus for pharmaceutical companies and regulatory entities [23]. Microsphere dosage forms provide distinct advantages over traditional pills, tablets and capsules due to their ability to be mixed with liquids (e.g. formulas, electrolyte drinks) and soft foods (e.g. applesauce, yogurt, milkshakes). Encapsulation with microsphere also provides the opportunity to taste-mask foul-tasking APIs. Furthermore, the present analysis provides encouraging progress on the intersection between dispersed dosage formats, taste-masking and bioequivalence.

\section{Acknowledgement}

The work presented in the current study was a culmination of support to Orbis Biosciences, Inc. from the Eunice Kennedy Shriver National Institute of Child Health and Human Development (NICHD), as a Phase II SBIR, 2R44HD074326-02 and 5R44HD074326-03 and resources provided by the Arkansas Children's Research Institute. The authors would like to thank Mrs. Amy Patton and Samantha Hewett for providing analytical support.

\section{References}

1. Sohi H, Sultana $Y$, Khar $R$ (2004) Taste masking technologies in ora pharmaceuticals: Recent developments and approaches. Drug Development and Industrial Pharmacy 30(5): 429-448. https://www.ncbi.nlm.nih.gov/pubme $\mathrm{d} /$ ?term $=$ Taste+masking+technologies+in+oral+pharmaceuticals\%3A+recent+ developments+and+approaches

2. Walsh J, Cram A, Woertz K, Breitkreutz J, Winzenburg G, et al. (2014) Playing hide and seek with poorly tasting paediatric medicines: do not forget the excipients. Advanced Drug Delivery Reviews 73: 14-33. https://www.ncbi.nlm. nih.gov/pubmed/?term=Playing+hide+and+seek+with+poorly+tasting+paediat ric+medicines $\% 3 \mathrm{~A}+$ do+not+forget+the+excipients.

3. Gittings S, Turnbull N, Roberts C, Gershkovich P (2014) Dissolution methodology for taste-masked oral dosage forms. Journal of Controlled Release 173: 32-42. https://www.ncbi.nlm.nih.gov/pubmed/24184344

4. Food and Drug Administration (2003) Guidance for industry: bioavailability and bioequivalence studies for orally administered drug products-genera considerations. Food and Drug Administration: Washington, DC. https://www. fda.gov/ohrms/dockets/ac/03/briefing/3995B1_07_GFI-BioAvail-BioEquiv.pdf

5. Kristensen $\mathrm{H}$ (2000) WHO guideline development of paediatric medicines: Points to consider in pharmaceutical development. International Journal of Pharmaceutics 435.2 (2012): 134-135. https://www.ncbi.nlm.nih.gov/ pubmed/22883696

6. Guideline ICH Harmonised Tripartite (2000) ICH Topic E11: Clinica Investigation of Medicinal Products in the Paediatric Population. CPMP/ 
Citation: Shoults CC, Kearns GL, Meyer AR, Moran J, D’Ann P, et al. (2017) Pharmacokinetics of a Taste-Masked Prednisone Oral Microsphere Powder. J Bioequiv Availab 9: 547-554. doi: 10.4172/jbb.1000360

ICH/2711/992001. http://www.ema.europa.eu/docs/en_GB/document_library/ Scientific_guideline/2009/09/WC500002926.pdf

7. Food and DrugAdministration (2013) Guidance for Industry Pediatric Study Plans: Content of and Process for Submitting Initial Pediatric Study Plans and Amended Pediatric Study. Plans. Rockville, MD: Food and Drug Administration. https:// www.fda.gov/downloads/drugs/guidancecomplianceregulatoryinformation/ guidances/ucm360507.pdf

8. Matsui D (2007) Current issues in pediatric medication adherence. Pediatric Drugs 9(5): 283-288. https://www.ncbi.nlm.nih.gov/pubmed/17927300

9. Ivanovska V, Rademaker C, van Dijk L, Mantel-Teeuwisee A (2014) Pediatric drug formulations: A review of challenges and progress. Pediatrics 134(2): 361 372. http://pediatrics.aappublications.org/content/134/2/361

10. ZajicekA, Fossler M, Barrett J, Worthington J, Ternik R, et al. (2013)A report from the pediatric formulations task force: perspectives on the state of child-friendly oral dosage forms. The AAPS Journal 15(4): 1072-1081. https://www.ncbi.nlm. nih.gov/pubmed/?term=A+report+from+the+pediatric+formulations+task+force $\% 3 A+$ perspectives+on+the+state+of+child-friendly+oral+dosage+forms

11. Mitchell J, Counselman F (2003) A taste comparison of three different liquid steroid preparations: prednisone, prednisolone, and dexamethasone. Academic Emergency Medicine 10(4): 400-403. https://www.ncbi.nlm.nih.gov/pubmed/? term $=\mathrm{A}+$ taste+comparison+of+three+different+liquid+steroid+preparations $\% 3$ $\mathrm{A}+$ prednisone $\% 2 \mathrm{C}+$ prednisolone $\% 2 \mathrm{C}+$ and + dexamethasone

12. Nicklaus S, Boggio V, Issanchou S (2005) Les perceptions gustatives chez l'enfant [Gustatory perceptions in children]. Archives de Pédiatrie 12(5): 579584. https://www.researchgate.net/publication/245954458_Les_perceptions_ gustatives_chez_l'enfant

13. Mennella J, Roberts K, Mathew P, Reed D (2015) Children's perceptions about medicines: individual differences and taste. BMC Pediatrics 15(1): 130. https:// www.ncbi.nlm.nih.gov/pubmed/26391354

14. Berkland C, Kim K, Pack D (2003) PLG microsphere size controls drug release rate through several competing factors. Pharmaceutical Research 20(7): 10551062. https://www.ncbi.nlm.nih.gov/pubmed/12880292
15. Berkland C, King M, Cox A, Kim K, Pack D (2002) Precise control of PLG microsphere size provides enhanced control of drug release rate. Journal of Controlled Release 82(1): 137-147. http://www.sciencedirect.com/science/ article/pii/S0168365902001360

16. Berkland C, Kim K, Pack D (2004) Precision polymer microparticles for controlled-release drug delivery in Carrier-Based Drug Delivery. American Chemical Society Symposium Series eBooks (Chapter 14, pp. 197-213). http:// pubs.acs.org/doi/abs/10.1021/bk-2004-0879.ch014

17. Kearns G, Bai S, Shoults C, Pierce D, Dormer N (2017) Palatability of a novel oral prednisone formulation: A matter of good taste. Clinical Pharmacology \& Therapetutics 2017 Apr; 69(4): 489-496. https://www.ncbi.nlm.nih.gov/ pubmed/28271493

18. Food and Drug Administration. (2016) Draft Guidance on Prednisone. Food and Drug Administration, Washington, DC. https://www.fda.gov/downloads/Drugs/ GuidanceComplianceRegulatoryInformation/Guidances/UCM481947.pdf

19. Food and Drug Administration (2003) Guidance for industry: Bioavailability and bioequivalence studies for orally administered drug products-general considerations. Food and Drug Administration, Washington, DC. https://www fda.gov/ohrms/dockets/ac/03/briefing/3995B1_07_GFI-BioAvail-BioEquiv.pdf

20. Food and Drug Administration (2003) Guidance for industry: Bioavailability and bioequivalence studies for orally administered drug products-general considerations. Food and Drug Administration, Washington, DC. https://www. fda.gov/ohrms/dockets/ac/03/briefing/3995B1_07_GFI-BioAvail-BioEquiv.pdf

21. Cram A, Bartlett J, Heimlich J (2013) Oral multiparticulates as a flexible solid dosage form approach for paediatric use. BioPharm Asia. https://biopharmaasia.com/magazine-articles/oral-multiparticulates-as-a-flexible-solid-dosageform-approach-for-paediatric-use/

22. Jenkins J, Sampson $P$ (1967) Conversion of cortisone to cortisol and prednisone to prednisolone. British Medical Journal 2(5546): 205-207. https://www.ncbi. nlm.nih.gov/pmc/articles/PMC1841223/

23. Turner M, Catapano M, Hirschfeld S, Giaquinto C (2014) Paediatric drug development: the impact of evolving regulations. Advanced Drug Delivery Reviews 73: 2-13. https://www.ncbi.nlm.nih.gov/pubmed/24556465. 